\title{
Effective bicultural leadership: A way to restore harmony at school and avoid suspension
}

\author{
Mere Berryman and Sonja Bateman
}

A $s$ the founding document of this country the Treaty of Waitangi can provide all New Zealanders, especially those seeking equity, with clear guidance and support to reflect the three Treaty principles of partnership, protection, and participation in their workplace. The principle of partnership is about responding to issues of power sharing and decision making. The principle of protection is about acknowledging and valuing indigenous knowledge and pedagogical values. Participation is the principle that provides individuals and groups with equity of access to resources and services.

This paper examines how a mainstream school principal supported by a Māori elder undertook hui whakatika procedures with teachers and family, rather than standing down or suspending a group of boys. Thus, both the Treaty of Waitangi and indigenous knowledge—specifically, Māori knowledge—was used to inform a process of working together to claim equity for Māori.

Before examining this particular case, we consider the relevance to it of Māori knowledge systems, in particular Durie's (2006) contemplation of understanding others, in the context of pōwhiri and the marae ātea.

\section{Māori knowledge}

As a nation that speaks of inclusion, social justice, and equity for all, it is worth our considering what these concepts might actually mean for Māori in terms of how Māori knowledge has been acknowledged throughout history. Despite the growing kaupapa Māori movement over the past 20 to 30 years, and Durie's (1997) assertion that Māori knowledge has an integrity of its own, Māori knowledge, beliefs, and understandings are still regularly relegated to the margins, perceived as inferior and lacking in any real substance, or simply dismissed.

Despite this, Bishop (1996) contends that solutions and understandings for Māori do not reside within the culture that has traditionally marginalised Māori; rather, the solutions and understandings for resolving issues faced by many Māori are located within Māori culture itself. Speaking from an educational perspective, Bishop, Berryman, Tiakiwai, and Richardson (2003) emphasise the benefits that can emerge when both traditional and contemporary Māori cultural knowledge, practices, and experiences are drawn upon. According to Gordon (1997), while cultural understandings emerging from the experiences of indigenous minorities may challenge mainstream perspectives, this does not mean that such perspectives should be ignored. Indeed, Howitt and Owusu-Bempah (1994) further contend that the lack of attention to alternatives to mainstream knowledge will leave any discipline (including the discipline of education) impoverished. For many Māori, the term mainstream in itself maintains the perspective that Māori knowledge belongs elsewhere, that to actually be and live as Māori necessitates belonging elsewhere as, generally, mainstream society neither reflects nor values understandings that are uniquely Māori.

Phinney and Rotheram (1987) argue that there are ethnically linked ways of thinking, feeling, and acting that are acquired through socialisation. The message implicit in this statement has profound implications for educators, given that education seeks to understand and respond to students' experiences in order to educate. Understanding others depends on three specific components, as outlined by Durie (2006). These components involve engagement, ways of thinking and theorising, and ways of analysing. Durie explores the marae ātea during the process of pōwhiri (rituals of encounter) as a metaphor for engagement, wherein particular aspects such as space, boundaries, and time exact particular significance and meaning.

\section{Space, boundaries, and time}

In describing the notion of space, Durie (2006) contends that a realistic degree of distance is necessary at the outset until a relationship has formed. Acknowledging a level of distance effectively provides a stage for clarifying the terms under which parties come together 


\section{... the traditional}

\section{hui, or meeting}

held within

\section{Māori cultural}

\section{protocols or ways}

of engagement,

\section{can provide}

\section{a supportive}

\section{and culturally}

\section{grounded space}

\section{for seeking}

\section{and achieving}

\section{resolution,}

\section{and restoring}

\section{harmony.}

and engage. Conversely, diminished distance may precipitate panic or alternatively lead to withdrawal, both of which impact negatively on the processes for building relationships and establishing engagement. Understanding the concept of boundaries requires ongoing attention to the distinctions between groups, that is, tangata whenua (hosts) and manuhiri (visitors); the living and the dead; the right and the left; safe and unsafe; men and women; the old and the young. Appreciation of these distinctions enables mutually respected boundaries to be defined without pretence, and can provide a more respectful platform upon which relationships can be built and engagement may emerge. Appreciating the notion of time, from a Māori perspective, means that being on time is less important than allocating, taking, or expanding time in order to ensure that important processes are acknowledged, completed properly, and accorded the time that they deserve.

For many Māori, the same rituals or phases of engagement as those progressed during the pōwhiri process can be applied during other situations or contexts of encounter. Guided by notions of space, boundaries, and time, these phases broadly include:

- starting/opening rituals (which includes respecting space and boundaries at the outset, and determining who speaks and when)

- clarifying and declaring who one is by acknowledging where one has come from

- clarifying and declaring intentions (which includes the purpose of meeting)

- coming together as a group

- building relationships and making initial connections (which includes sharing one's whakapapa or genealogical connections)

- addressing the particular kaupapa or issue (which includes taking the time that is required for open and frank discussions, face-to-face interactions, reaching decisions and agreements, and defining particular roles and responsibilities)

- concluding (which includes summarising decisions and agreements, and reasserting mana or personal prestige)

- sharing kai/refreshments.

\section{Hui whakatika}

Macfarlane (1998) proposes that the traditional hui, or meeting held within Māori cultural protocols or ways of engagement, can provide a supportive and culturally grounded space for seeking and achieving resolution, and restoring harmony. In contexts such as these, hui whakatika can offer a unique process for restoring harmony from within legitimate Māori spaces (Hooper, Winslade, Drewery, Monk, \& Macfarlane, 1999). Underpinned by traditional or pre-European Māori concepts of discipline, hui whakatika provide a process that follows the same phases of engagement as those outlined above, while also adhering to four typical features of pre-European Māori discipline as identified by Olsen, Maxwell, and Morris (cited in McElrea, 1994):

- an emphasis upon reaching consensus through a process of collaborative decision making involving members of the whole community

- a desired outcome of reconciliation and a settlement that is acceptable to all parties rather than isolating and punishing the offender

- not apportioning blame but examining the wider reason for the wrong with an implicit assumption that there was often wrong on both sides

- less concern with whether or not there had been a breach of law and more concern with the restoration of harmony.

The four broad concepts of reaching consensus, reconciliation, examination, and restoration are critical to effective hui whakatika. It is important to note also that these traditional Māori disciplinary concepts continue to feature widely in contemporary Māori society as a means of resolving issues of concern or conflict.

Hui whakatika therefore can be likened to contemporary notions of restorative justice (Hooper et al., 1999). Indeed, it may be argued that the aims of both processes are fundamentally similar. Restorative practice in schools requires:

... that harm done to a relationship is understood and acknowledged and that effort is made to repair that harm. In order for that restoration to happen, the voices of those affected by the offence need to be heard in the process of seeking redress. (Restorative Practices Development Team, 2003, p. 11)

What differs however is that the initiation and legitimation of the hui whakatika process is able to be determined by and for Māori. Thus, hui whakatika can exemplify how all three Treaty principles (partnership, protection, participation) may be able to be applied in practice.

There are four distinct phases to a hui whakatika process:

1. the pre-hui phase: preparing the groundwork, the planning, and preparation that aims to ensure the work is undertaken in 
true partnership and aimed at the most successful outcomes for all parties

2. the hui phase (the hui proper): making connections with others who are involved, setting the direction, and formulating roles and responsibilities; throughout the hui phase, cultural processes are followed:

beginning the hui

- mihimihi (greetings)/karakia (prayer)

response from manuhiri

reiterating the purpose of the hui

whakawhanaungatanga (introductions and making connections)

sharing food

developing the hui

how we are being affected, how we are feeling

successes to date, strengths

barriers to success

seeking out a new story (restorying), by determining and agreeing on the way forward: what we will do, who will do what...

setting a time and venue for forming and consolidating the plan

closing the hui (poroporoaki/rituals of farewell)

whakakapi (summing up)

final comments by members

karakia

3. forming/consolidating the plan

4. follow-up and review (at a later date).

In line with Durie's domains of space, boundaries, and time, and according to Macfarlane (2007), each of these four phases is critical to the overall success of a hui whakatika. It is imperative that sufficient time and effort is invested in the initial pre-hui phase, as this part of the process is equally as important as the actual hui itself. The pre-hui phase involves determining who needs to be involved, establishing a willingness from all parties to participate in this process of making amends, meeting with all parties separately in order to explain the process and preparing them for what will happen in the hui, hearing their stories about what has happened and, finally, selecting a venue and time. Phase two of the process, the hui proper, follows the protocols of engagement as represented by a pōwhiri process. Effective facilitation of this phase is also crucial.

These four phases are now used to present a case study in which bicultural leadership provided a way to develop new understandings and effectively restore harmony in a mainstream school.

\section{Hui whakatika highlighting principal and kaumātua leadership and partnership}

This hui whakatika concerns one Māorimedium syndicate within a large mainstream school. Given the trust and respect the principal held for the Māori community, and in order to "protect time for teaching and learning by reducing external pressures and interruptions and establishing an orderly and supportive environment both inside and outside classrooms" (Robinson, 2007, p. 8), this principal opted to work in partnership with Māori. The traditional process of hui was used to resolve a situation that involved three Year 7 and Year 8 Māori students found to have been experimenting with marijuana during the school day and in the school grounds.

\section{Phase 1: The pre-hui phase}

The teachers-who were Māori-and the Pākehā principal sought advice from a kaumātua (elder) directly connected to the local hapū (sub-tribe) - a woman held in very high regard within both the Māori and non-Māori communities. Her advice resulted in the staff members, the three students, and members of their families agreeing to come to a meeting at the school the very next week. This group understood, albeit some of them with scepticism, that the meeting would be held according to Māori protocol in order to seek solutions by engaging within the supportive and culturally appropriate learning contexts provided by the traditional hui (Macfarlane, 1998). The group also understood that the school policy response would normally have been to suspend the boys, thus removing them from the education setting and potentially exposing them to even greater risk of drug abuse. The teachers and the families involved wanted to avoid this situation at all costs. The principal understood that support from this kaumātua on previous occasions, using traditional Māori responses, had already provided some effective solutions. Although this situation was very different from the others he had encountered, he trusted that a traditional Māori response could indeed be very effective.

\section{Phase 2: The hui phase}

At the direction of the kaumātua, family members accompanied each of the three boys, including a grandmother who was there for her own mokopuna (grandchild) as well as for the other boys. The principal, deputy principal, senior teacher, classroom teacher, and the kaumātua all attended. Participation of this kaumātua ensured that correct kawa or cultural protocols were adhered to, thus protecting both the people and the kaupapa (purpose/agenda). She began the meeting with mihimihi, then karakia that asked for guidance and support. This was followed by a cup of tea before the agenda was jointly set. All members of the hui agreed that they would be seeking to fully address the problem without creating a situation of shame and blame. The principal gave his clear commitment to support whatever decisions came from the meeting, thus handing the power to redress the situation and restore relationships back to the hui participants. After much discussion and at times extremely heated debate, the marijuana incident was fully discussed, ownership was acknowledged, and consequences were collaboratively determined and agreed to. The students involved in the incident, and their parents, contributed to both the debate and the determining of solutions and consequences. The hui continued with tasks being agreed to and allocated and then it was time for poroporoaki when everyone was given an opportunity to have their final say. The meeting then concluded with a karakia.

\section{Phase 3: Forming/consolidating the plan}

As a result of the collaborative decision making within the hui, the group planned a four-day inschool suspension intervention, to be developed by the teachers and supported on a daily basis by a person from each boy's family. Teachers agreed to set up the separate programme aimed at providing these three students with positive Māori cultural messages and role models, as well as specific and accurate information about marijuana and the consequences of drug abuse. The students went home from the hui with family members, and then returned the next day ready for their four days within the newly determined parameters of the in-school suspension.

The plan focused on three key areas:

- accurate information (about marijuana and the implications of its use)

- open and honest sharing of information (between the specific school staff, the boys, and their parent(s); amongst parents; and between related professionals)

- keeping the boys in the education system (the alternative would almost certainly have been suspension).

Each of the four days of the in-school suspension began with the senior teacher and kaumātua 


\section{By developing}

\section{and maintaining}

\section{relationships of trust}

\section{and respect with}

\section{cultural experts}

\section{and others, and by}

seeking to work

\section{within these cultural}

\section{spaces, opportunities}

\section{arise which enable}

\section{individuals to see}

\section{themselves in}

\section{relation to others and}

\section{to learn from these}

\section{relationships. Within}

\section{these spaces, one is}

\section{able to bring one's}

\section{self, and all}

\section{that that represents,}

\section{to the kaupapa, and}

be listened to. meeting with the boys and their family member for karakia. The day's work and timetable were then discussed. On the bell, they each returned with their work to one of the three syndicate classrooms and seated themselves in their desk placed to the rear of the room. Here, the boys each worked on their individual programme under the further guidance and support of the family member who had agreed to support them on that day. Four visitors, who were able to speak knowledgeably on the effects of marijuana, had each been invited to share their expertise at lunchtime sessions. These visitors were all Māori; their involvement had been organised by the kaumātua from her strong local networks. They included another kaumātua with a young, recovering drug user, a Māori Youth Aid Officer, a doctor, and a man working in the field of drug rehabilitation. At lunchtime on each of the four days, the boys came together with members of their own family and the teachers. The boys, their family members, and the teachers shared food, attended each of the four related presentations facilitated by these visitors, listened, questioned, and talked openly and honestly.

Although the rest of the students in the syndicate undoubtedly knew what had happened and was happening, the syndicate teachers did not discuss any of these events with them; nor did the principal discuss these events at a staff level. Interactions between these boys and their classmates were greatly reduced over the four days of the in-class suspension and although teachers did not actively monitor this, it was promoted by the classmates themselves. On the Friday afternoon exactly one week after the marijuana incident, the in-class suspension ended; after the weekend the boys resumed their usual relationships with their peers and school returned to normal.

\section{Phase 4: Follow-up and review}

This response ensured that these students remained at school and after the in-school detention they were accepted back by their classmates as if nothing untoward had happened. Importantly, this response opened up more effective two-way communication and support between the homes of these students and their school. All groups learnt from the process, the outcome was seen by all to be just and equitable relevant to the misdemeanour, and, more importantly, none of the groups (school, student, or family members) lost mana.

This incident happened a decade ago. The boys all remained at school until at least the end of Year 11. The youngest of the three boys successfully finished his Year 12 having competed in top college sports and cultural teams throughout his secondary schooling. For these boys, no repeat incidents such as this were reported as having occurred throughout the rest of their schooling.

\section{Conclusion}

For Māori who are working to support the learning and cultural needs of Māori students in mainstream settings, following principles from te ao Māori can pose many challenging dilemmas. In terms of the Treaty of Waitangi principles of participation and protection, many Māori educators strive to ensure that the students and their whānau with whom they work are able to access all of the resources and benefits available from within the New Zealand education system. Simultaneously, they work to protect and revitalise their own cultural identity and integrity, as well as the cultural identity and integrity of others with whom they work. These activities are regularly positioned within the spaces between the minority/indigenous Māori and the dominant Pākehā cultures (Durie, 2003) and, within these spaces, cultural constructs such as pōwhiri and hui can provide legitimate spaces, determined and governed by Māori culture and protocols. These are the spaces from which enormous learning and strength for both groups may be drawn.

By developing and maintaining relationships of trust and respect with cultural experts and others, and by seeking to work within these cultural spaces, opportunities arise which enable individuals to see themselves in relation to others and to learn from these relationships. Within these spaces, one is able to bring one's self, and all that that represents, to the kaupapa, and be listened to. Power is able to be shared between self-determining individuals and/or groups. Participants are able to determine their own actions within relationships of interdependence (Bishop, Berryman, Powell, \& Teddy, 2007; Young, 2005) that are culturally prescribed and understood. Too often, Māori have not been accorded respectful or legitimate partnership space within New Zealand society, regularly being relegated to the position of junior partner (O'Sullivan, 2007). Rather than continue to perpetuate such disparity, a determination to reclaim legitimate spaces and protocols, as supported by this principal and facilitated by the kaumātua, is necessary.

Pōwhiri and hui whakatika therefore can provide a powerful analogy for the notion of claiming spaces as they both provide distinctive protocols for establishing relationships (Glynn, 
Berryman, Walker, Reweti, \& O’Brien, 2001), that are based on mutual respect and trust, but also on rangatiratanga (self-determination). Traditionally, mainstream education has perpetuated power imbalances that have only served to denigrate and marginalise indigenous knowledge and practices (Bishop \& Glynn, 1999; Mead, 1997; Smith, 1999). For many Pākehā, pōwhiri and hui whakatika will require a shift in mindset, away from the familiar ways in which they prefer to engage in Māori or Pākehā spaces to learning how to engage respectfully in legitimate Māori cultural spaces.

Within this hui whakatika, what was acceptable and not acceptable was defined within Māori ways of understanding. These cultural contexts, led by cultural experts, ensured that no one voice was able to dominate. Instead, each member brought their own set of experiences and expertise, and participation evolved on the basis of interdependent roles and responsibilities within which trust, respect, and obligations to each other and to the kaupapa were fundamental to the collective vision of restoring harmony and respecting the mana of all participants.

In Article One of the Treaty of Waitangi, the Crown undertook to enter into a partnership with Māori; under Article Two, the Crown declared that Māori would receive protection and the right to define and retain all of their possessions; and under Article Three, Māori were guaranteed participation in, or access to, all of the benefits that the Crown had to offer. Throughout the decades, Māori people have continually tried to assert their rights under the Treaty of Waitangi, rights which enable them to both define and promote Māori knowledge and pedagogy. Within the legitimate Māori spaces provided by this hui whakatika, Māori were indeed able to claim these rights and reach resolutions that were of benefit to them, while at the same time having their mana maintained. Rather than denigrate or marginalise the Pākehā who participated, these cultural spaces were inclusive-all were able to participate and learn.

The people in this hui whakatika were looked after by leaders who understood the importance of mana. The principal acknowledged that the mana of these students would not be upheld within the context of stand down or suspension; thus he sought out and supported an alternative solution. The kaumātua ensured that all of the appropriate traditional practices and protocols, including those implicit in traditional Māori discipline, were employed throughout the intervention. This in turn ensured the safety of all and the ultimate success of the intervention.
The effective bicultural partnership led by the principal and kaumātua in this case can provide others with a model to restore harmony and avoid suspension. Ten years later cases such as this are still the exception in mainstream schools rather than a new norm. The reassertion of Māori cultural aspirations, preferences, and practices, supported and legitimised by cultural leaders, can lead to more effective participation and learning for Māori students (Bishop \& Glynn, 1999), but only when we as educators are open to new possibilities.

\section{References}

Bishop, R. (1996). Whakawhanaungatanga: Collaborative research stories. Palmerston North: Dunmore Press.

Bishop, R., Berryman, M., Powell, A., \& Teddy, L. (2007). Te Kōtahitanga: Improving the educational achievement of Māori students in mainstream education Phase 2: Towards a whole school approach: Report to the Ministry of Education. Wellington: Ministry of Education.

Bishop, R., Berryman, M., Tiakiwai, S., \& Richardson, C. (2003). Te Kōtahitanga: Experiences of Year 9 and 10 Māori students in mainstream classrooms: Final report to the Ministry of Education. Wellington: Ministry of Education.

Bishop, R., \& Glynn, T. (1999). Culture counts: Changing power relations in education. Palmerston North: Dunmore Press.

Durie, M. (1997). Identity, access and Māori advancement. Paper presented at the New Zealand Educational Administration Society (An Indigenous Future) conference, Auckland Institute of Technology.

Durie, M. (2006, October). Foundations for psychological and social interventions with Mãori. Presentation at Compass Professional Development Seminar, Auckland Institute of Technology.

Durie, M. H. (2003, March). Māori educational advancement at the interface between te ao Māori and te ao whānui. Paper presented at the Hui Taumata Mātauranga Tuatoru, Turangi and Taupo.

Glynn, T., Berryman, M., Walker, R., Reweti, M., \& O'Brien, K. (2001, July). Partnerships with indigenous people: Modifying the cultural mainstream. Keynote address at the Partnerships in Educational Psychology conference, Brisbane.

Gordon, E. (1997). Task force on the role and future of minorities. Educational Researcher, 26(3), 44-53.

Hooper, S., Winslade, J., Drewery, W., Monk, G., \& Macfarlane, A. (1999, July). School and family group conferences: Te Hui Whakatika (a time for making amends). Paper presented at the Keeping Young People in School Summit Conference on Truancy, Suspensions and Effective Alternatives, Auckland.

Howitt, D., \& Owusu-Bempah, J. (1994). The racism of psychology. London: Routledge.

Macfarlane, A. (1998, November). Hui: A process for conferencing in schools. Paper presented at the Western Association for Counselor Education and Supervision conference, Seattle.

Macfarlane, A. (2007). Discipline, democracy, and diversity: Working with students with behaviour difficulties. Wellington: NZCER Press.

McElrea, F. (1994). The intent of the Children, Young Persons and Their Families Act 1989. Restorative justice? Youth Law Review, July/ Aug/Sept, 4-9.

Mead, L. T. (1997). Ngā aho o te kākahu mattauranga: The multiple layers of struggle by Māori in education. Unpublished doctoral thesis, University of Auckland.

O'Sullivan, D. (2007). Beyond biculturalism: The politics of an indigenous minority. Wellington: Huia Publishers.

Phinney J., \& Rotheram, M. (1987). Children's ethnic socialization: Pluralism and development. Newbury Park, CA: Sage Publications.

Restorative Practices Development Team. (2003). Restorative practices for schools. Hamilton: University of Waikato.

Robinson, V. (2007). School leadership and student outcomes: Identifying what works and why. (ACEL Monograph Series No. 41). Winmalee, NSW: Australian Council for Educational Leaders.

Smith, L. T. (1999). Decolonizing methodologies: Research and indigenous peoples. London \& New York: Zed Books; Dunedin: University of Otago Press.

Young, I. M. (2005). Self-determination as nondomination. Ethnicities, 5(2): 139-159.
Mere Berryman is director of the Ministry of Education (Special Education) Poutama Pounamu Education Research and Development Centre in Tauranga.

Email: mere.berrymanळminedu.govt.nz

Sonja Bateman works for the Ministry of Education (Special Education).

Email: sonja.batemanळminedu.govt.nz 